\title{
Optimization of seismic response of steel structure using negative stiffness damper
}

\author{
Priyanka A. Jadhav ${ }^{1}$. Suhail Ahmed Shaikh ${ }^{2}$
}

Received: 30 May 2018 / Accepted: 29 July 2019 / Published online: 13 August 2019

(c) The Author(s) 2019

\begin{abstract}
Earthquakes of greater magnitude can cause stark destruction. Seismic protection of structures is one important tool to minimize damages and total collapse of structures. Researchers have made many attempts to achieve this goal with various techniques and one such strategy of seismic response control developed is introducing true negative stiffness in the structure. True negative stiffness is introduced with the help of negative stiffness damper (NSD). The NSD generates force in the direction of the displacement and hence it is called negative stiffness. The present study focuses on modelling NSD device in a commercial software tool (ETABS 2016). Further the device is implemented on 2D steel frame models and seismic parameters such as base shear, storey displacement and top storey acceleration are studied.
\end{abstract}

Keywords Negative stiffness damper $\cdot$ Seismic response control

\section{Introduction}

During last two to three decades, the reduction of structural response caused by dynamic effects has become a subject of intensive research. Many structural control concepts have been evolved for this purpose, and quite a few of them have been implemented in practice. They include reduction of undesirable vibrational levels of flexible structures due to unexpected large environmental loads, retrofitting existing structures against environmental hazards, protecting seismic equipment and important secondary systems and provision of new concepts of design of structures against environmental loading. These structural control systems can be broadly classified into active control, passive control, semi-active control and hybrid control systems. An alternative approach is to "simulate yielding" by introducing true negative stiffness at prescribed displacement leading to the concept of "apparent weakening". This is achieved with negative stiffness devices (NSD).

Priyanka A. Jadhav

priyankajadhaviitb@gmail.com

1 Department of Civil Engineering, Terna Engineering College, Navi Mumbai, Maharashtra, India

2 Department of Civil Engineering, Saraswati College of Engineering, Navi Mumbai, Maharashtra, India
Soong and Spencer (2000) studied active, semi-active and hybrid control of structures with seismic applications. Reinhorn et al. (2005) introduced the concept of weakening and damping to reduce the acceleration, base shear and deformations of the structure. Bhaskararao and Jangid (2005) investigated the effectiveness of friction dampers in mitigating the seismic responses of connected structures under various earthquakes. Igarashi et al. (2008) presented a study on seismic response control with innovative negative stiffness dampers (NSD) to reduce absolute acceleration of the girder. Pasala et al. (2013) was first to introduce the concept of true negative stiffness for structural applications. A detailed description of the operation, component function, and design of the device is presented in the paper (Fig. 1). Gisha et al. (2015) studied the performance of true negative stiffness (TNS) and an adaptive negative stiffness system (ANSS) on five degrees of freedom shear structure. The optimal values of parameters and optimal number of dampers are studied based on the response such as inter storey drifts, accelerations, displacements, and base shear. Heysami (2015) investigated types of dampers and their performance during earthquake. The types of dampers studied are friction, metal, viscous, visco-elastic, shape memory alloys and mass dampers. Pasala et al. (2016) presented an experimental study of a modelled seismically isolated 3 -story structure equipped negative stiffness device to reduce the response of the structure 


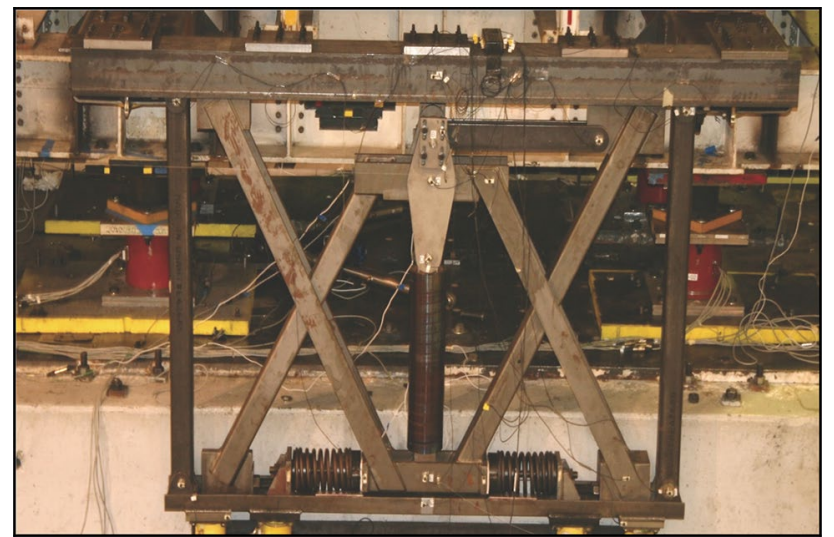

Fig. 1 A view of negative stiffness damper (Pasala et al. 2013)

and presented comparisons of analytical and experimental results to validate the analytical models of the negative stiffness device. Onkar et al. (2016) implemented negative stiffness device (NSD) to a RC structural frame in the form of chevron bracings using SAP 2000. Mirza Arif and Chakrabarti (2017) presented optimal use of NSD for seismic resistant frames. The negative stiffness equations of NSD were solved in MATLAB and the results were used as a NSD tool in SAP2000.

Based on the literature review implementation of NSD device analytically on 2D and 3D models using software tools is ongoing work. Attempts to do the same are on at present. The proposed work will focus on implementing the device on 2D and 3D steel frames using software tools and the same will be studied for different time history loadings. The main aim of the present research is to study the seismic response of steel structure with NSD using ETABS 2016. In the proposed work analytical model of NSD is studied and modeled in ETABS 2016 Software. The NSD is implemented on 2D and 3D steel frames and its effects on the seismic response are studied for three earthquake ground motions viz, Corralit, Holliste and Sylmar. Based upon the reduction in three parameters viz, base shear, storey acceleration and storey displacement the optimal placement of NSD will be decided. However, the same can be used in RCC structures by introducing ANSS but the scope of this work is limited to application on steel structure.

The NSD is a device that generates force in the direction of impending motion. It can be applied and installed in between the floors or in between the ground floor and isolation level. The NSD is shown in Figs. 1 and 2. The part of the NSD incorporates a highly compressed machined spring (CS) that develops a force in the direction of motion which gives negative stiffness. The magnitude of the force reduces with increasing displacement so that stability of the system is ensured at large displacements. A double chevron selfcontaining system to resist the preload in the compressed

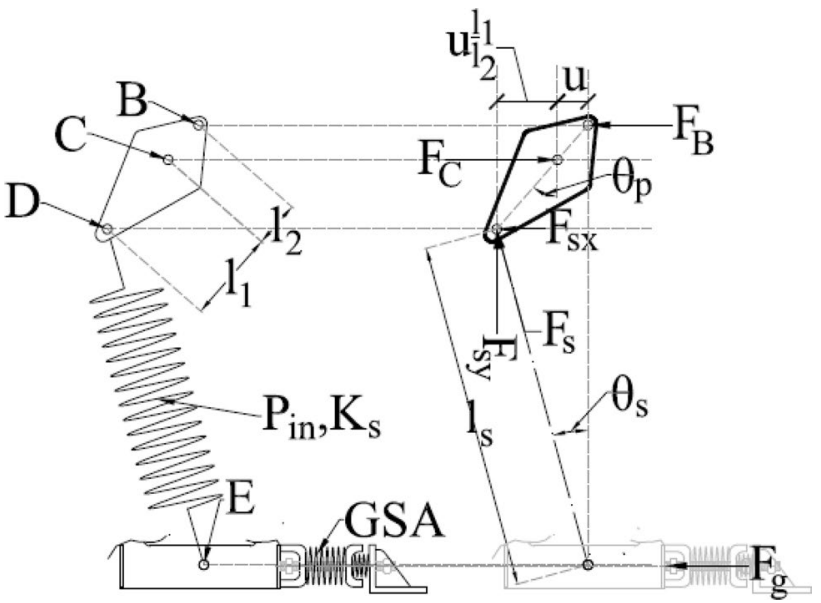

Fig. 2 NSD centre mechanism (Pasala et al. 2013)

spring. A system (called gap spring assembly or GSA) that provides positive stiffness up to a predefined displacement.

\section{Analytical model of NSD}

Analysis of the NSD requires consideration of kinematics and equilibrium of forces in the deformed configuration. Consider the free body diagram of the pivot plate shown in Fig. 2. The forces acting on the pivot plate (FB, FC and Fs) are shown. The figure also shows the GSA force $F_{\mathrm{g}}$ which does not act on the pivot plate.

The force displacement relationship of negative stiffness damper can be given as: (Pasala et al. 2013)

$F_{\mathrm{NSD}}=\left(\frac{P_{\mathrm{in}}+K_{\mathrm{s}} l_{\mathrm{p}}}{l_{\mathrm{s}}}-K_{\mathrm{s}}\right)\left(\frac{l_{1}}{l_{2}}\right)\left(2+\frac{l_{2}}{l_{1}}+\frac{l_{\mathrm{p}}+l_{1}}{\sqrt{l_{2}^{2}-u^{2}}}\right) u+F_{\mathrm{g}}$,

where $\quad F_{\mathrm{g}}=\left\{\begin{array}{cc}k_{\mathrm{g} 1} u, & 0 \leq u \leq d_{\mathrm{gap}} \\ k_{\mathrm{g} 1} d_{\mathrm{gap}}+k_{\mathrm{g} 2}\left(u-d_{\mathrm{gap}}\right) & u>d_{\text {gap }}\end{array}\right\}$.

The above equations are solved using the PYTHON code and the results are shown below. As an example, Table 1 presents the nominal properties of the NSD used for solving mathematical equations in programming language PYTHON. From the above equation it is clear that the main parameter defining negative stiffness is stiffness of the pre-compressed spring $\left(K_{\mathrm{s}}\right)$ and NSD spring preload $\left(P_{\text {in }}\right)$. Optimizing these parameters first gives best possible reduction in seismic response. Using these properties and developed equations of Pasala et al. (2013) calculations were performed and results are presented for 
Table 1 Nominal NSD properties (Pasala et al. 2013)

\begin{tabular}{llcl}
\hline Quantity & Symbol & Value & Units \\
\hline Length BC of pivot plate & $l_{1}$ & 25.4 & $\mathrm{~cm}$ \\
Length CD of pivot plate & $l_{2}$ & 12.7 & $\mathrm{~cm}$ \\
NSD spring length & $l_{\mathrm{p}}$ & 76.2 & $\mathrm{~cm}$ \\
NSD spring stiffness & $K_{\mathrm{s}}$ & 1.4 & $\mathrm{kN} / \mathrm{cm}$ \\
NSD spring preload & $P_{\text {in }}$ & 16.5 & $\mathrm{kN}$ \\
Double hinged column height & $h$ & 124.5 & $\mathrm{~cm}$ \\
Lever length & $l_{\mathrm{lv}}$ & 67.3 & $\mathrm{~cm}$ \\
NSD engagement displacement & $u_{y}^{\prime}$ & 1.65 & $\mathrm{~cm}$ \\
GSA spring S1 stiffness & $k_{\mathrm{s} 1}$ & 4.9 & $\mathrm{kN} / \mathrm{cm}$ \\
GSA spring S2 stiffness & $k_{\mathrm{s} 2}$ & 0.3 & $\mathrm{kN} / \mathrm{cm}$ \\
GSA spring S2 preload & $P_{\text {is } 2}$ & 8.1 & $\mathrm{kN}$ \\
\hline
\end{tabular}

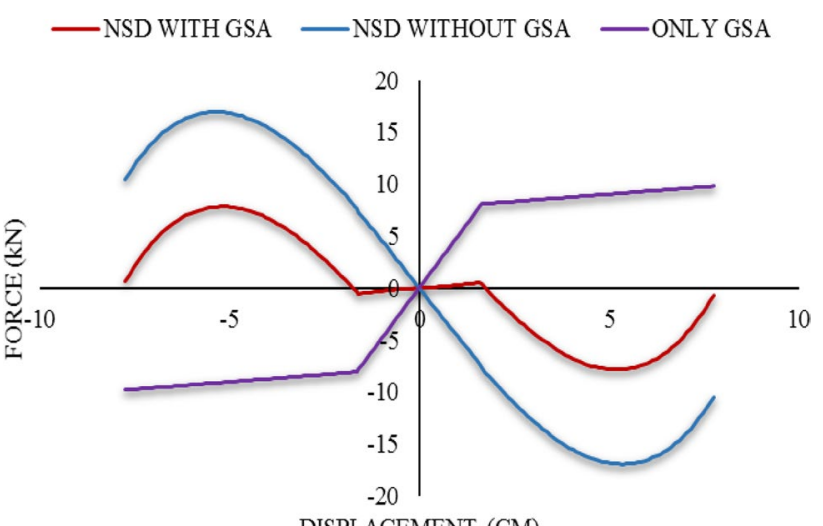

Fig. 3 Force displacement relationship obtained from results of PYTHON

GSA force-displacement relation based on Eq. (2), NSD force-displacement relation without the GSA based on Eq. (1) with $F_{g}=0$ and NSD force-displacement relation with the GSA based on Eqs. (1) and (2).
Figure 3 shows the force displacement relationship obtained from results of PYTHON of NSD with gap spring assembly, without gap spring assembly and only gap spring assembly, respectively. NSD with GSA is used as link element in ETABS 2016.

\section{Negative stiffness device (link element) in ETABS 2016}

Equation (1) is solved using Python code in the present study. However, one can use Matlab or even excel sheets to solve the NSD equation. The results of the solved equation can be used in any commercial software package which has the ability to model nonlinear force displacement relation of NSD. ETABS 2016 has one such element. Multilinear elastic element in ETABS 2016 can be used to model nonlinear force displacement relation given by Eq. (1). Negative stiffness damper can be modeled as a multi-linear elastic link in ETABS 2016. Taking non linearity in $U_{2}$ ( $X$ axis of the link element in ETABS 2016) direction taking effective stiffness and effective damping as zero. Figure 4 a shows the snapshot of the property inputs of the link element in ETABS 2016 used for 2D model considering the parameters of Pasala et al. (2013). Figure 4b shows the snapshot of the property inputs of the Link element in ETABS 2016 used for 3D model considering the parameters of Gisha et al. (2015) (Table 2).

\section{Analytical study}

To analyse $\mathrm{G}+4$ storey $2 \mathrm{D}$ steel frame and $\mathrm{G}+3$ storey 3D steel building under time history analysis in ETABS 2016 for studying the effectiveness of NSD and comparison between seismic response reduction in the form of base shear, storey displacements and top storey acceleration. A G +4 story $2 \mathrm{D}$ steel frame fixed at supports, having a bay width of $5 \mathrm{~m}$ ( $X$-direction) and story height of $3 \mathrm{~m}$ is taken up for study.
Fig. 4 Link element graph in ETABS 2016 a for 2D model, b for 3D model

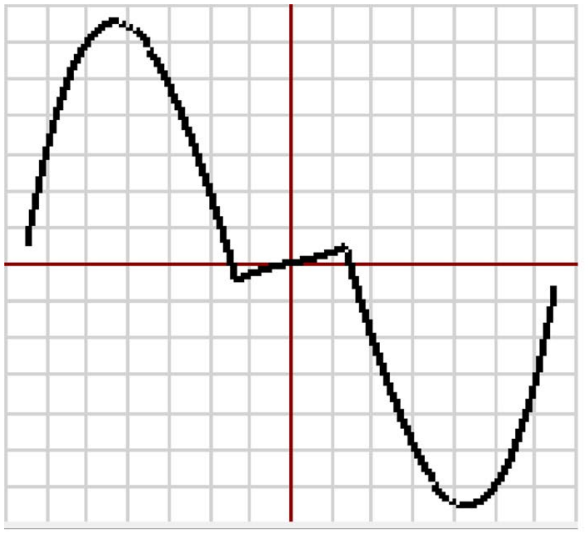

(a)

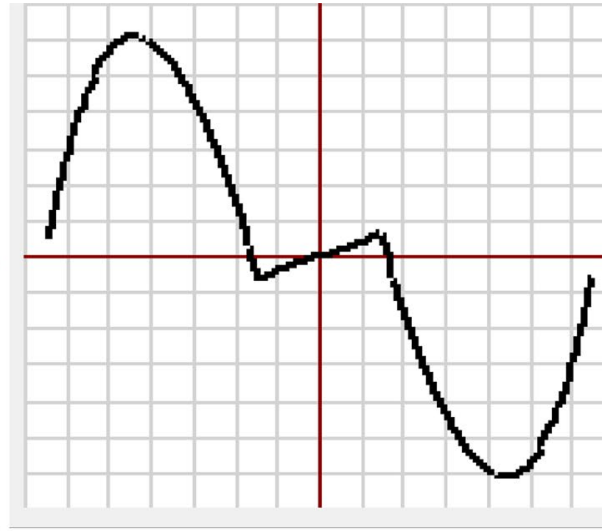

(b) 
Table 2 Properties of NSD used in the force-displacement expression (Gisha et al. 2015)

\begin{tabular}{ll}
\hline Parameter & Value \\
\hline Distance from spring to fixed pin $\left(l_{1}\right)$ & $0.5842 \mathrm{~m}$ \\
Distance from lever pin to fixed pin $\left(l_{2}\right)$ & $0.2921 \mathrm{~m}$ \\
Spring length $\left(l_{\mathrm{s}}\right)$ & $1.7526 \mathrm{~m}$ \\
Gap opening $\left(d_{\text {gap }}\right)$ & $0.01651 \mathrm{~m}$ \\
GSA stiffness for spring $1 k_{\mathrm{g} 1}$ & $1050.72 \mathrm{kN}$ \\
GSA stiffness for spring $2 k_{\mathrm{g} 2}$ & $28.02 \mathrm{kN}$ \\
The initial pre-compression force in the spring $P_{\text {in }}$ & $95 \mathrm{kN}$
\end{tabular}

Beam ISMB 200 and column ISMB 225 with steel grade $\mathrm{Fe} 345$. The design considerations used are live load $-5 \mathrm{kN} / \mathrm{m}$, Self-weight is explicitly captured using steel density of value Fe345 grade steel in ETABS 2016, design code-IS1893 (part 1): 2016, special moment resisting frame, importance factor- 1 and seismic zone-zone-III, model considered are as follows.

Model 1 is the 2D frame of column ISMB 225 and beam ISMB 200 fixed at the base and it is considered as reference model without the application of NSD. Model 2 is the 2D frame of column ISMB 225 and beam ISMB 200 fixed at the base and NSD applied at ground floor level for Bay 1,
2 and 3 (Fig. 5). Model 3 is the 2D frame of column ISMB 225 and beam ISMB 200 fixed at the base and NSD applied at first floor level for Bay 1, 2 and 3 (Fig. 6). Model 4 is the 2D frame of column ISMB 225 and beam ISMB 200 fixed at the base and NSD applied at second floor level for Bay 1, 2 and 3 (Fig. 7). Model 5 is the 2D frame of column ISMB 225 and beam ISMB 200 fixed at the base and NSD applied at third floor level for Bay 1, 2 and 3 (Fig. 8). Model 6 is the 2D frame of column ISMB 225 and beam ISMB 200 fixed at the base and NSD applied at fourth floor level (Fig. 9).

The study is further extended by converting $2 \mathrm{D}$ model in 3D model which is of steel frame having beam ISMB 200 and column ISMB 225 with steel grade Fe345, frames are $5 \mathrm{~m}$ in $X$ and $Y$-direction and storey height is kept same as $3 \mathrm{~m}$ in $Z$-axis, respectively. Slab is modelled as a thin membrane member of thickness $150 \mathrm{~mm}$ and a concrete grade of M20. The model is fixed at the base. The self-weight of the frame is explicitly captured using the steel density value for the material in ETABS 2016. Live load of $5 \mathrm{kN} / \mathrm{m}^{2}$ is applied directly on slab. Negative stiffness damper is implemented at different positions described below.

Model 7 is the 3D frame of column ISMB 225 and beam ISMB 200 fixed at the base and it is considered as reference model without NSD. Model 8 is the 3D frame of column ISMB 225 and beam ISMB 200 fixed at the base and NSD
Fig. 5 Model 2 frame with NSD at GF a Bay 1, b Bay 2, c Bay 3

Fig. 6 Model 3 frame with NSD at FF a Bay 1, b Bay 2, c Bay 3

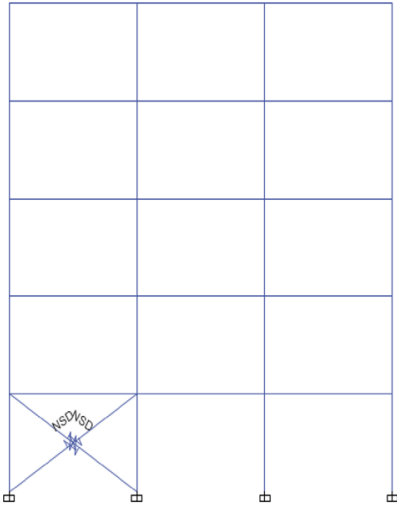

(a)

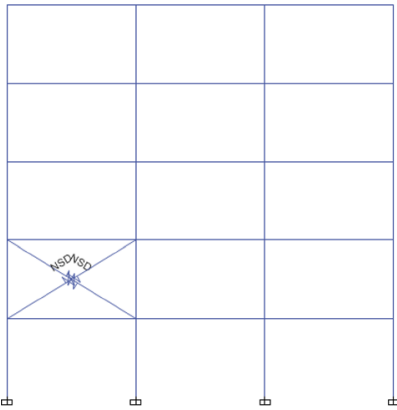

(a)

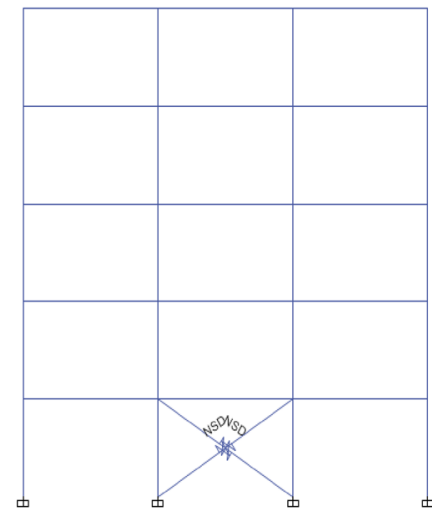

(b)

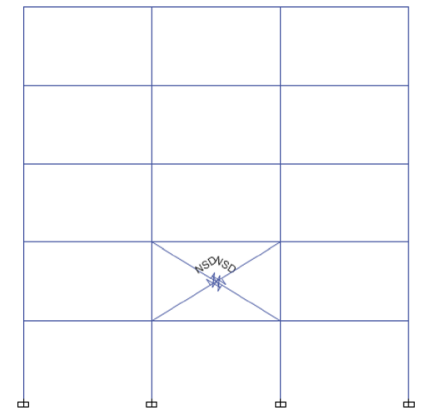

(b)

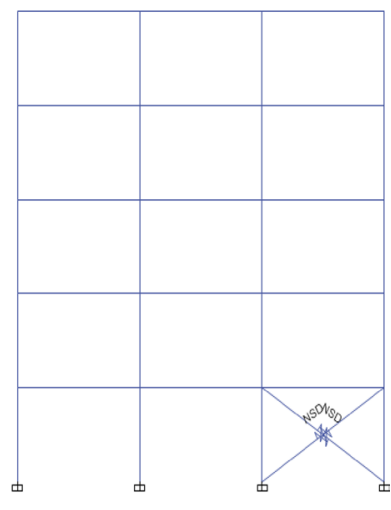

(c)

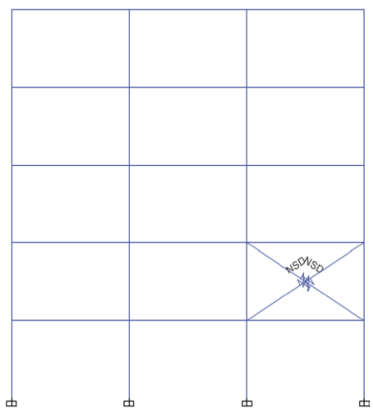

(c) 
Fig. 7 Model 4 frame with NSD at SF a Bay 1, b Bay 2, $\mathbf{c}$ Bay 3

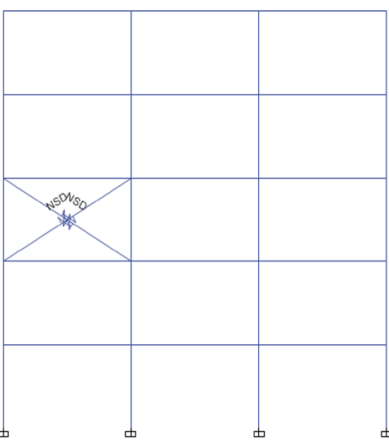

(a)

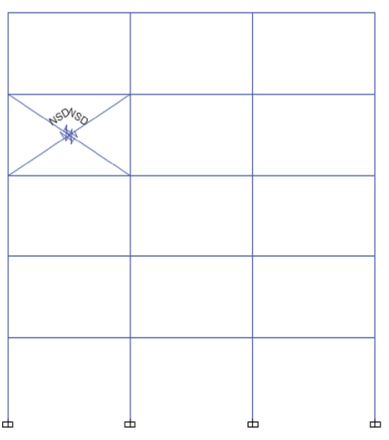

(a)

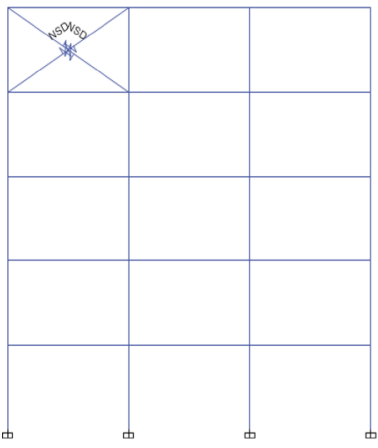

(a)

Fig. 9 Model 6 frame with NSD at 4th F a Bay 1, b Bay 2,

c Bay 3

Fig. 8 Model 5 frame with NSD at TF a Bay 1, b Bay 2, c Bay 3

applied at ground floor level for Bay 1, 2 and 3. Model 9 is the 3D frame of column ISMB 225 and beam ISMB 200 fixed at the base and NSD applied at first floor level for Bay 1,2 and 3. Model 10 is the 3D frame of column ISMB 225 and beam ISMB 200 fixed at the base and NSD applied at second floor level for Bay 1,2 and 3. Model 11 is the 3D frame of column ISMB 225 and beam ISMB 200 fixed at the base and NSD applied at third floor level for Bay 1, 2 and 3.

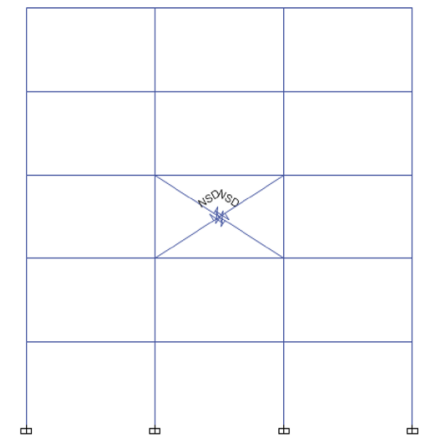

(b)

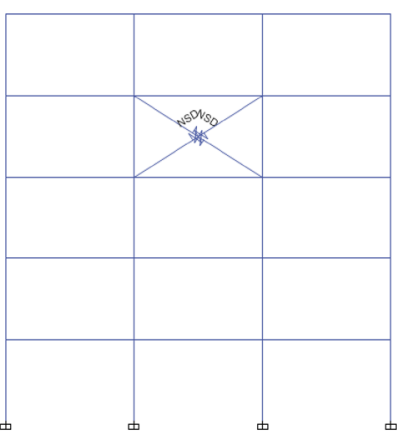

(b)

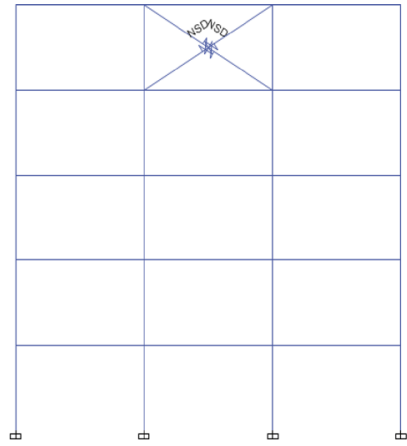

(b)

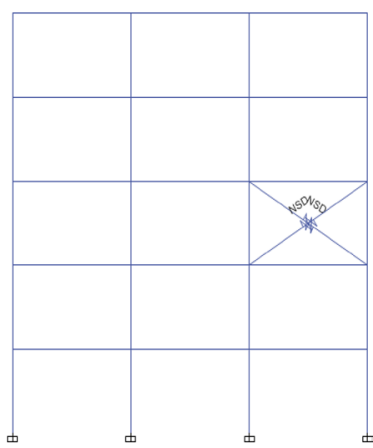

(c)

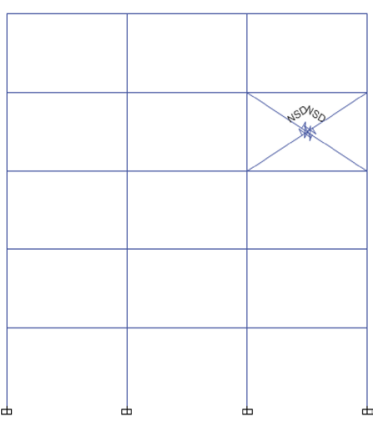

(c)

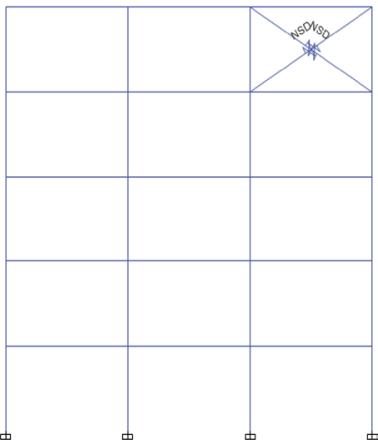

(c)

\section{Results and discussions}

Figures 10, 11 and 12 shows base shear of 2D model for Corralit, Holliste and Sylmar earthquake ground motion. The Figures shows a reduction in base shear of $15.96 \%$ when NSD is applied at ground floor of Bay 2 for Corralit time history load case, $37.61 \%$ when NSD is applied at 


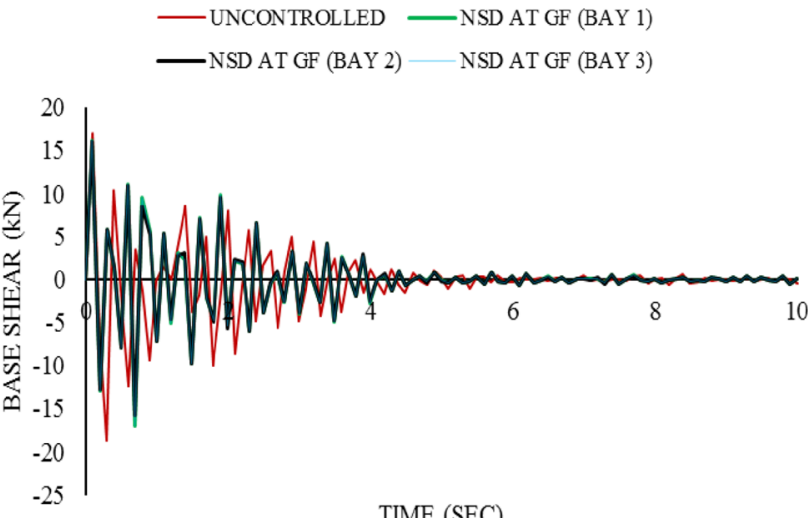

Fig. 10 Base shear of 2D model for Corralit time history

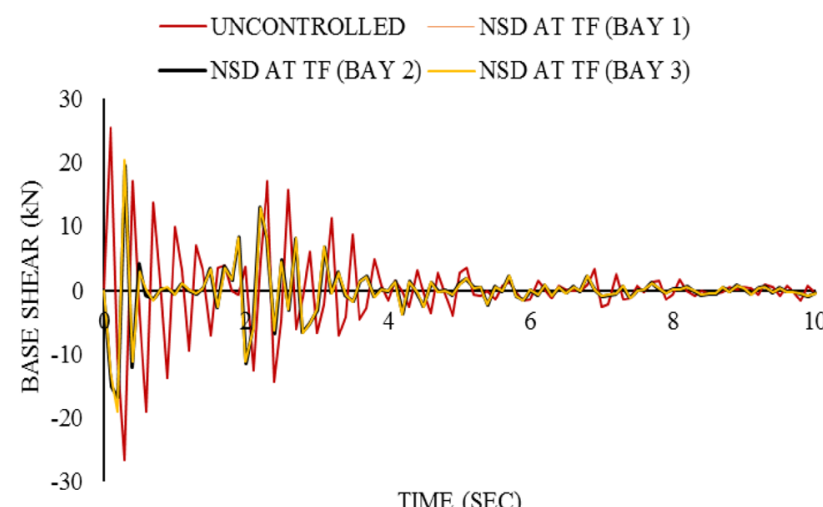

Fig. 11 Base shear of 2D Model for Holliste time history

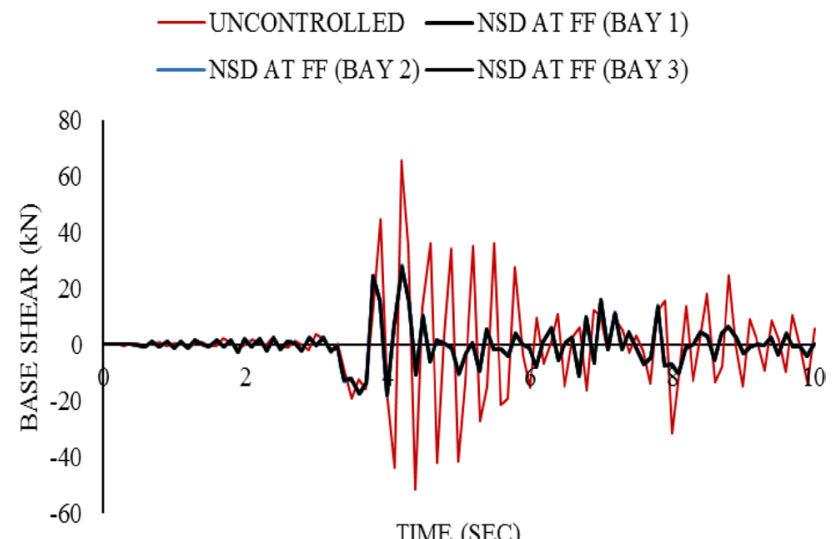

Fig. 12 Base shear of 2D model for Sylmar time history

third floor of Bay 2 for Holliste time history load case and $64.88 \%$ when NSD is applied at first floor of Bay 1 or Bay 3 for Sylmar time history load case.

Figures 13, 14 and 15 shows Base shear of 3D model for Corralit, Holliste and Sylmar earthquake ground motion. The Figures shows a reduction in base shear of $68.87 \%$ when

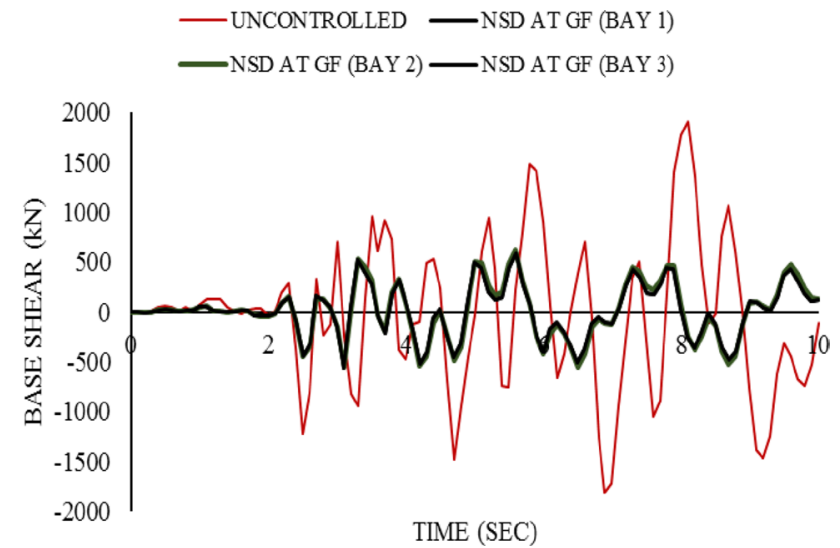

Fig. 13 Base shear of 3D model for Corralit time history

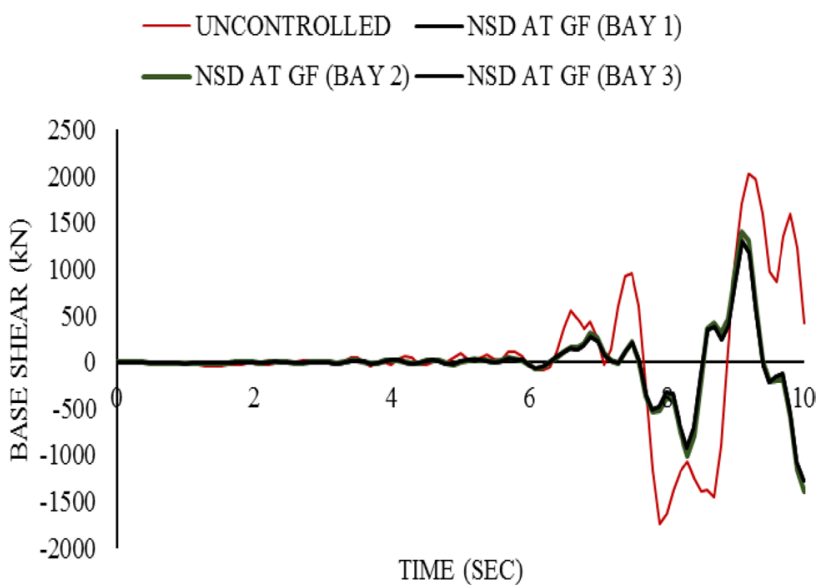

Fig. 14 Base shear of 3D model for Holiste time history

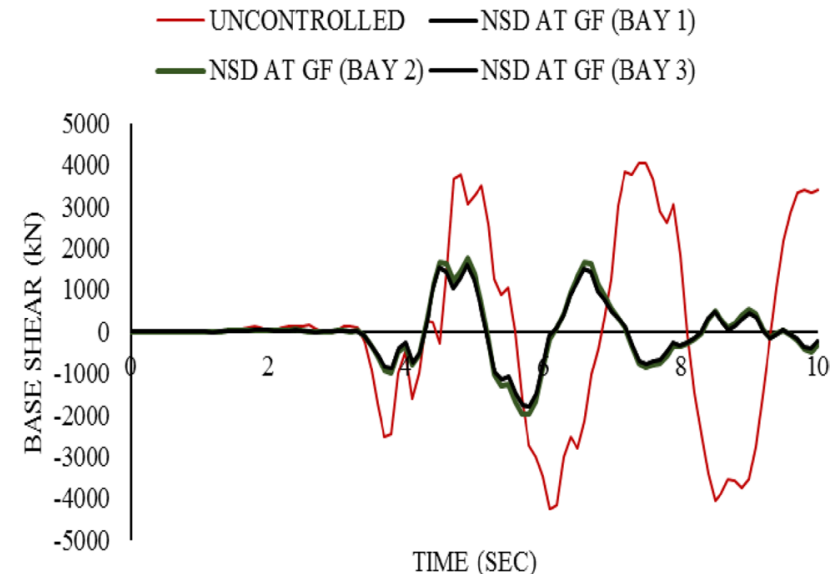

Fig. 15 Base shear of 3D model for Sylmar time history

NSD is applied at ground floor of Bay 1 or Bay 3 for Corralit time history load case, $26.89 \%$ when NSD is applied at ground floor of Bay 1 or Bay 3 for Holliste time history 


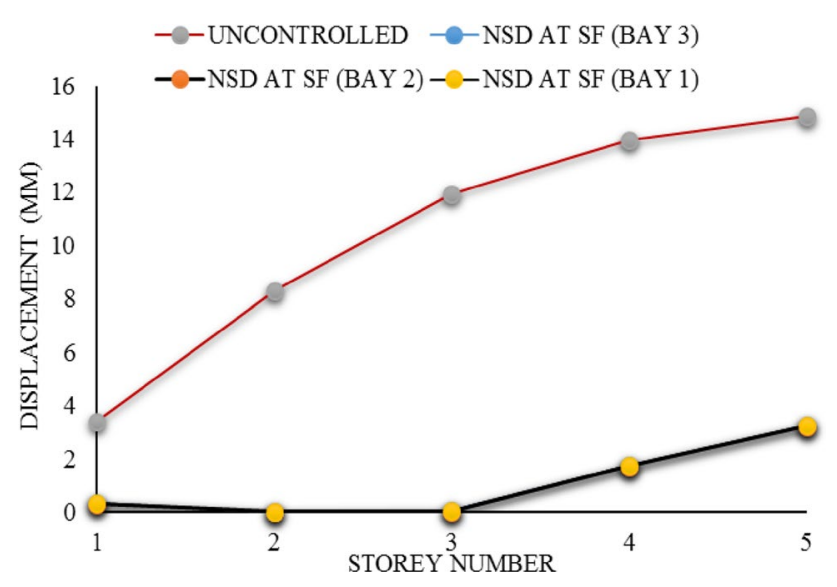

Fig. 16 Storey displacement of 2D model for Corralit time history

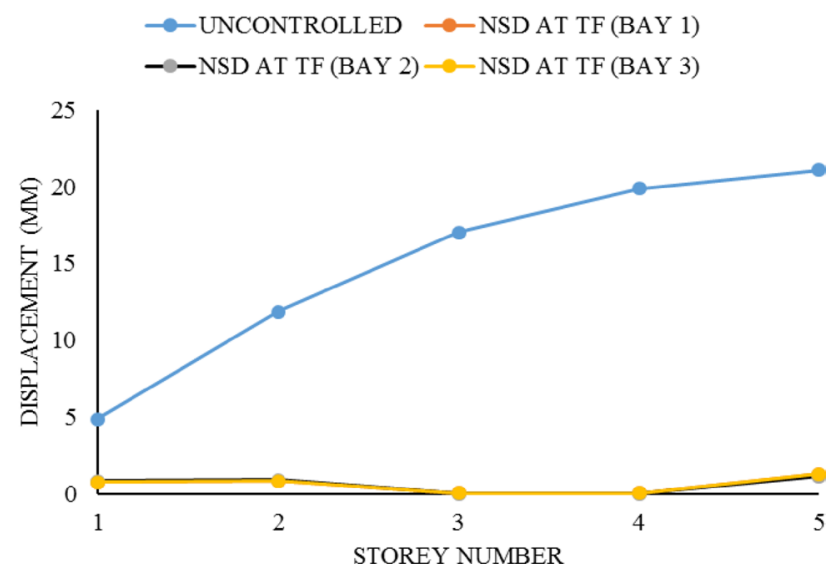

Fig. 17 Storey displacement of 2D model for Holliste time history

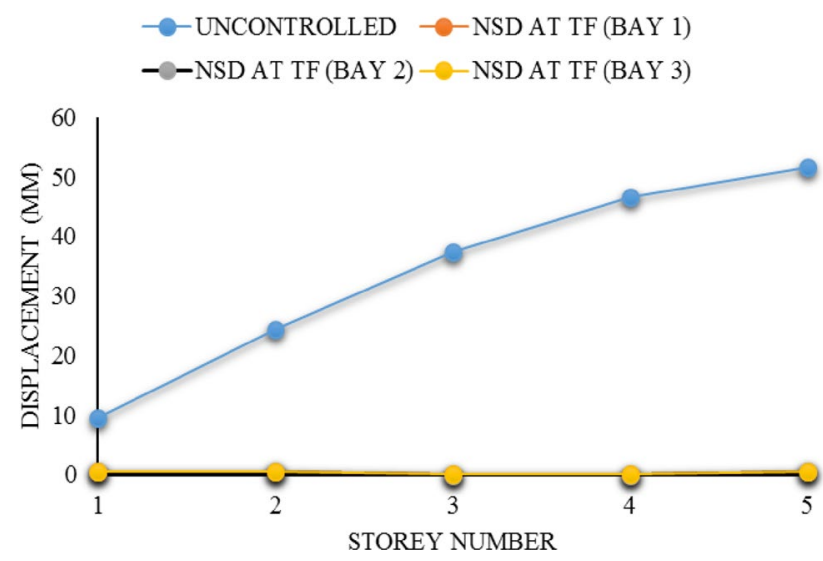

Fig. 18 Storey displacement of 2D model for Sylmar time history

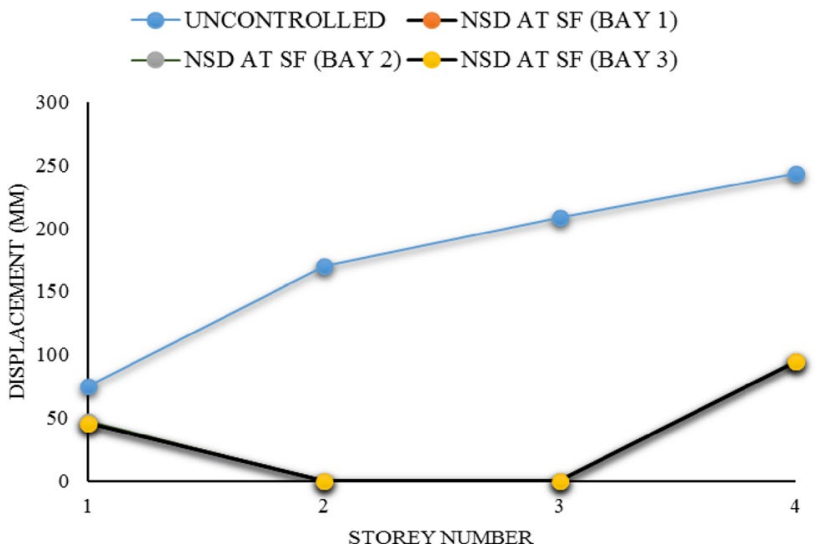

Fig. 19 Storey displacement of 3D model for Corralit time history

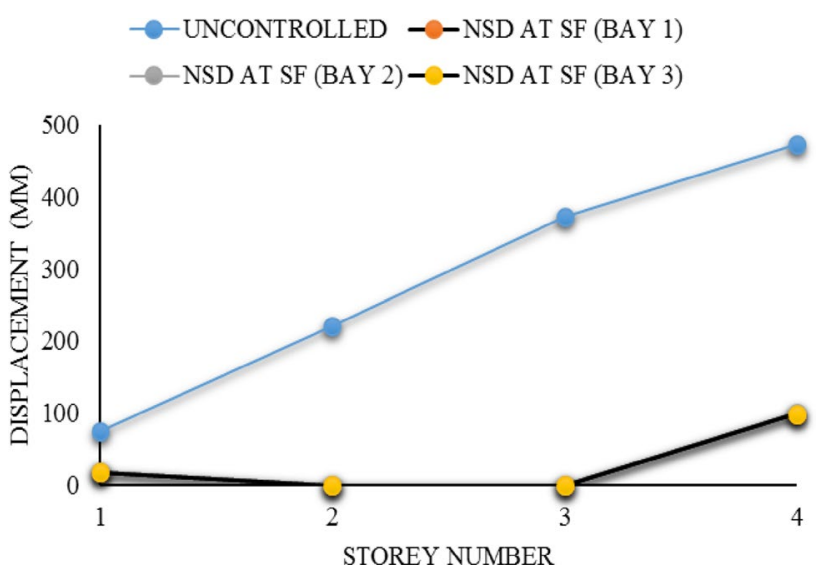

Fig. 20 Storey displacement of 3D model for Holliste time history

load case and $60.32 \%$ when NSD is applied at ground floor of Bay 1 or Bay 3 for Sylmar time history load case. Results obtained in Bay 1 or Bay 3 are of similar trend because of symmetry in structure.

Figures 16, 17 and 18 shows storey displacement of 2D model for Corralit, Holliste and Sylmar earthquake ground motion. The figure shows, that the optimum placement of NSD is at second floor of Bay 2 for Corralit, third floor of Bay 2 for Holliste and third floor of Bay 2 for sylmar time history load case, respectively, when storey displacement is considered. However, on the basis of base shear the optimum location decided was at ground floor of Bay 2 for Corralit, third floor of Bay 2 for Holliste and first floor of Bay 1 or Bay 3 (due to symmetry in the structure) for Sylmar time history load case. Thus, the response in storey displacement increases with this optimum location. As mentioned earlier in literature review that NSD has to be implemented in structure to reduce the responses for base shear and acceleration. This drawback can be overcome by adding additional passive dampers with NSD and the assembly is called as ANSS. 


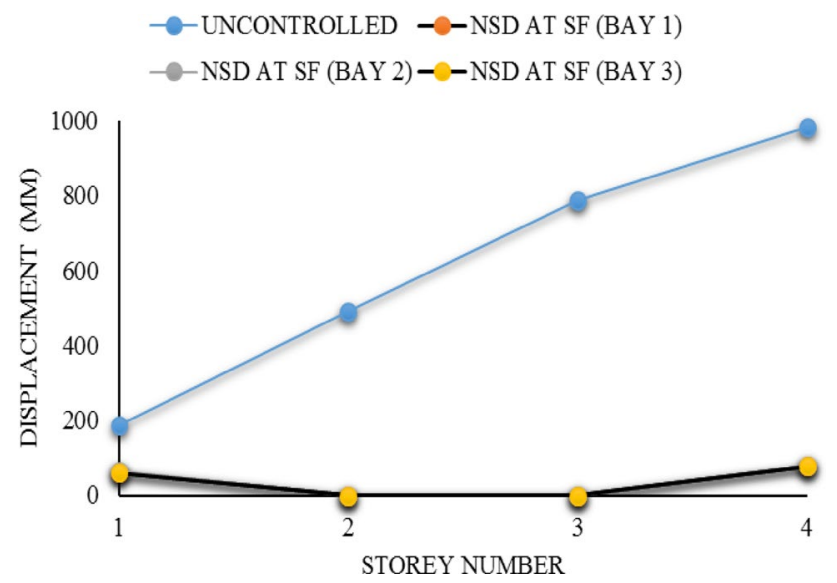

Fig. 21 Storey displacement of 3D model for Sylmar time history

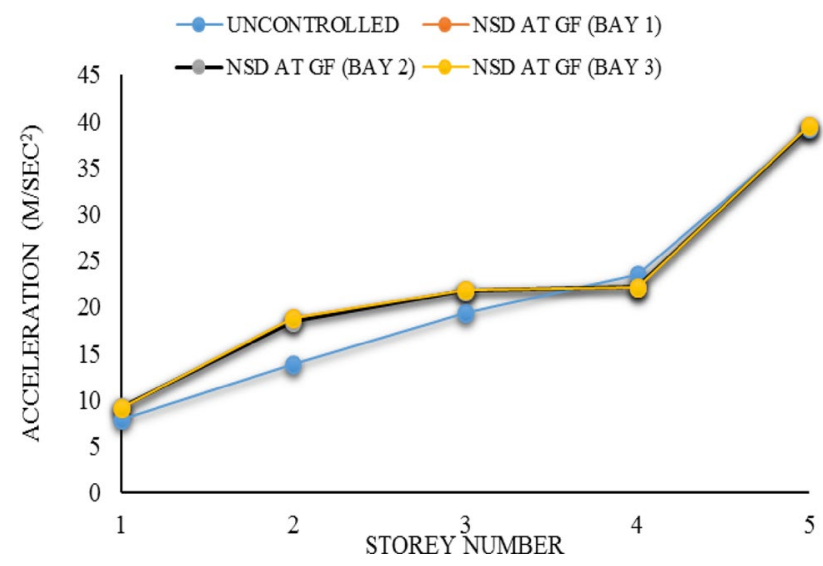

Fig. 22 Storey acceleration of 2D model for Corralit time history

Figures 19, 20 and 21 shows storey displacement of 3D model for Corralit, Holliste and Sylmar earthquake ground motion. The figure shows that the optimum placement of NSD is at second floor of Bay 1 or 3 (due to symmetry in the structure) for Corralit, Holliste and Sylmar time history load case, respectively, when storey displacement is considered. However, on the basis of base shear the optimum location decided was at ground floor of Bay 1 or 3 for Corralit, Holliste and Sylmar time history load case. Thus, the response in storey displacement increases with this optimum location. As mentioned earlier in literature review that NSD has to be implemented in structure to reduce the responses for base shear and acceleration. This drawback can be overcome by adding additional passive dampers with NSD and the assembly is called as ANSS.

Figures 22, 23 and 24 show storey acceleration of 2D model for Corralit, Holliste and Sylmar earthquake ground motion. The Figure shows that that the optimum placement for NSD is at ground floor of Bay 2 for Corralit, first floor of Bay 2 for Holliste and third floor of Bay 1 or Bay 3 for Sylmar time

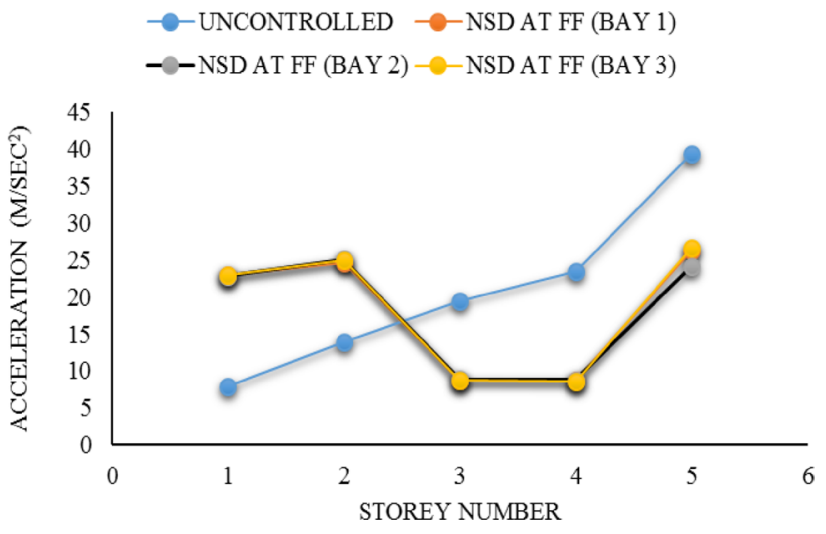

Fig. 23 Storey acceleration of 2D model for Holliste time history

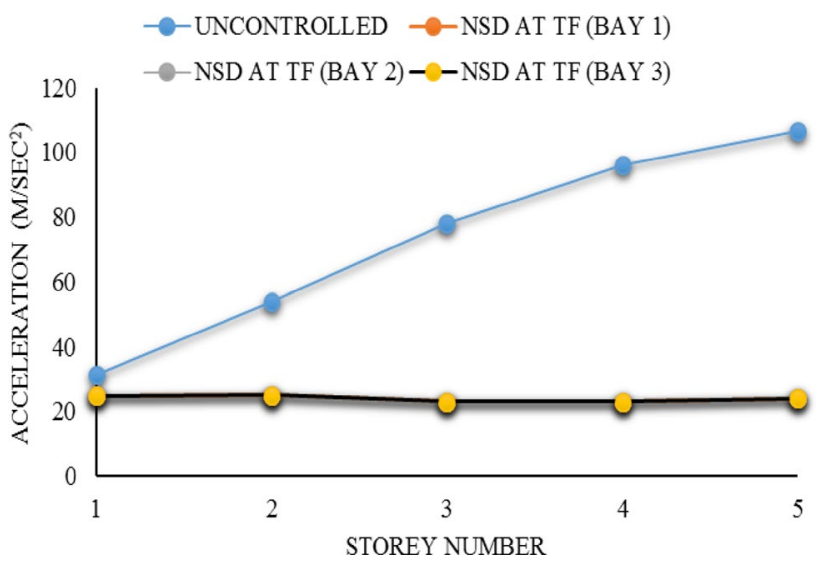

Fig. 24 Storey acceleration of 2D model for Sylmar time history

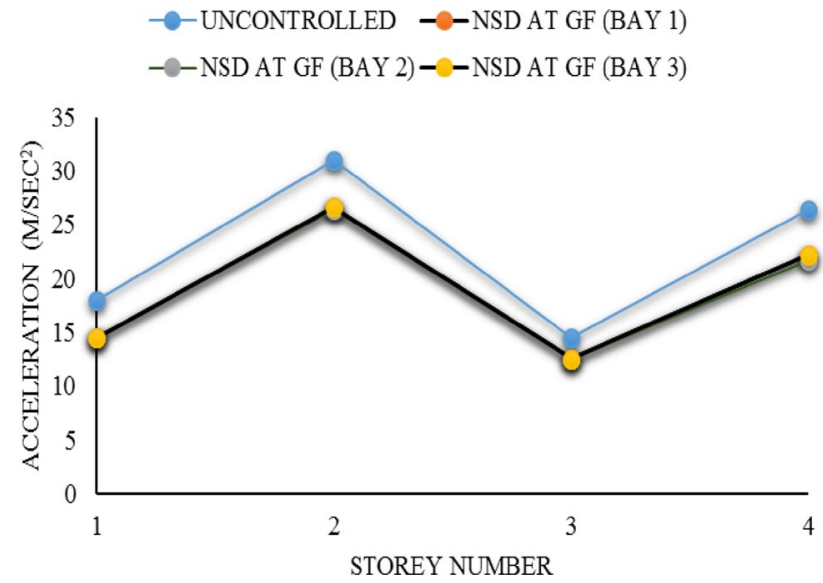

Fig. 25 Storey acceleration of 3D model for Corralit time history

history (TH) load case. Based upon the seismic response control obtained in base shear and story acceleration it can be concluded that the best possible location of the NSD in 2D model is ground floor of Bay 2 for Corralit, first floor of Bay 2 


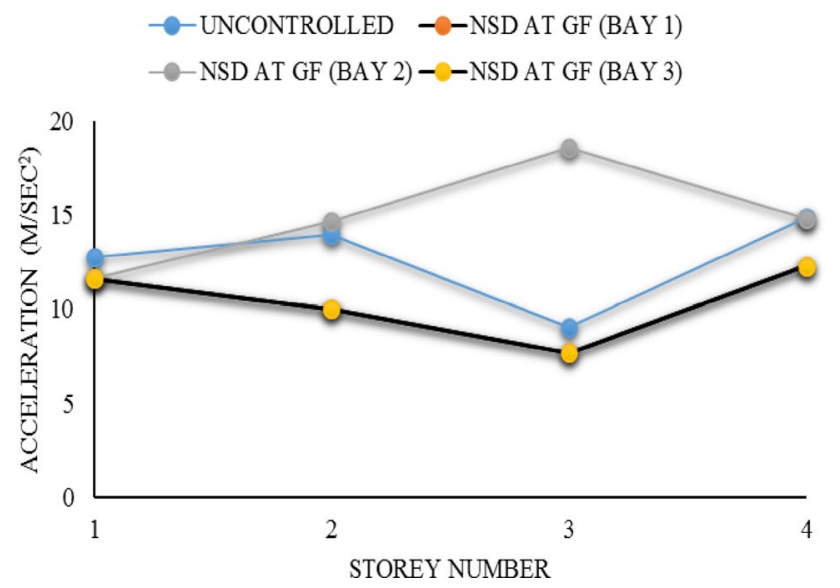

Fig. 26 Storey acceleration of 3D model for Holliste time history

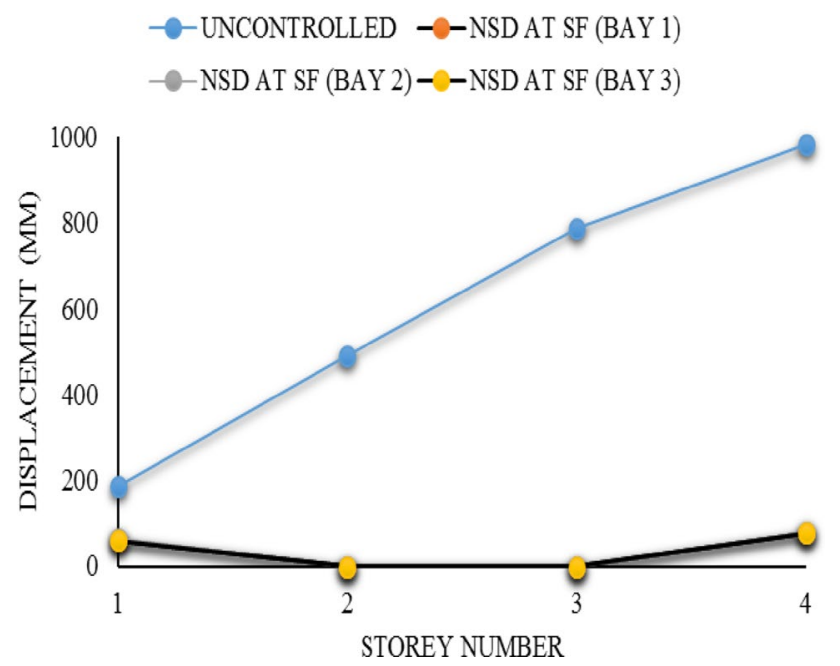

Fig. 27 Storey acceleration of 3D model for Sylmar TH load case

for Holliste and third floor of Bay 1 or Bay 3 for Sylmar time history load case, respectively.

Figures 25, 26 and 27 storey acceleration of 3D model for Corralit, Holliste and Sylmar earthquake ground motion. The figure shows that the optimum placement for NSD is at ground floor of Bay 1 or Bay 3 for Corralit, Holliste and Sylmar time history (TH) load case. Based upon the seismic response control obtained in base shear and story acceleration it can be concluded that the best possible location of the NSD in 3D model for Corralit, Holliste and Sylmar time history load case is at ground floor of Bay 1 or Bay 3 .

\section{Conclusions}

In the present study analysis of $2 \mathrm{D}$ steel frame and 3D steel building with and without NSDs are carried out using time history analysis in ETABS 2016 software. Three earthquake load histories are used viz, Corralit, Holliste and Sylmar. Based on the analytical study following conclusions are drawn:

- Negative stiffness damper helps to reduce the base shear and storey acceleration of 2D and 3D frames, respectively, from the results compared with models without NSD for all the three considered earthquake load history.

- Optimal position of NSD is decided based upon two seismic parameters namely base shear and storey acceleration.

- Based on the present study optimal location obtained of 2D model for Corralit earthquake time history is ground floor of Bay 2, Holliste earthquake time history is first floor of Bay 2 and Sylmar earthquake time history is third floor of Bay 1 or Bay 3, respectively.

- Based on the present study optimal location of 3D model for Corralit, Holliste and Sylmar earthquake time history is ground floor of Bay 1 or Bay 3.

- Results reveal that different NSD has to be modelled for different structures and for different locations of installation to obtain the best reduction in seismic response.

- Overall result shows that NSD increases the displacement at the level of installation of the device due to apparent weakening introduced by NSD. However, it can be controlled by using any passive damper in parallel with NSD.

Open Access This article is distributed under the terms of the Creative Commons Attribution 4.0 International License (http://creativeco mmons.org/licenses/by/4.0/), which permits unrestricted use, distribution, and reproduction in any medium, provided you give appropriate credit to the original author(s) and the source, provide a link to the Creative Commons license, and indicate if changes were made.

\section{References}

Bhaskararao AV, Jangid RS (2005) Seismic analysis of structures connected with friction dampers. Eng Struct 28:690-703

Gisha MM, Asim Q, Jangid RS (2015) Optimal placement of negative stiffness damping system. In: Proceedings of ASME 2015 conference on smart materials adaptive structures and intelligent systems, Colorado Springs, ASME Press, USA

Heysami A (2015) Types of dampers and their seismic performance during an earthquake. Curr World Environ 10:1002-1015

Igarashi H, Kouchiyama O, Toyooka A, Shimoda I (2008) Developement of the Friction-based Passive Negative Stiffness Damper 
and its Verification Tests using Shaking Table, Proc., 14th World Conference on Earthquake Engineering, Seismological Press of China, Beijing

Mirza Arif B, Chakrabarti MA (2017) Optimal use of negative stiffness damper for seismic resistant frames. IOSR J Mech Civ Eng 14:23-31

Onkar P, Tande SN, Kulkarni AB (2016) Concept of negative stiffness device in RC buildings in seismic areas. Int $\mathrm{J}$ Latest Trends Eng Technol 7(1):125-132

Pasala DTR, Sarlis AA, Nagarajaiah S, Reinhorn AM, Constantinou MC, Tayler D (2013) Negative stiffness device for seismic protection of structures. J Struct Eng (ASCE) 139(7):1112-1123

Pasala DTR, Sarlis AA, Nagarajaiah S, Reinhorn AM, Constantinou MC, Tayler D (2016) Negative stiffness device for seismic protection of structures: shake table testing of a seismically isolated structures. J Struct Eng (ASCE) 152(5):04016005-1-04016005-13
Reinhorn AM, Viti S, Cimellaro GP, Chrysostomou CZ (2005) Retrofit of structures: strength reduction with damping enhancement. In: 37th joint meeting of US-Japan panel on wind and seismic effects, UNJR. Public Works Research Institute, Tsukuba, https://www. pwri.go.jp/eng/ujnr/joint/37/37.htm

Soong TT, Spencer BF (2000) Active, semi-active and hybrid control of structures. In: 12th World conference of earthquake engineering, Auckland, New Zealand. New Zealand Society for Earthquake Engineering, Upper Hutt, N.Z

Publisher's Note Springer Nature remains neutral with regard to jurisdictional claims in published maps and institutional affiliations. 